
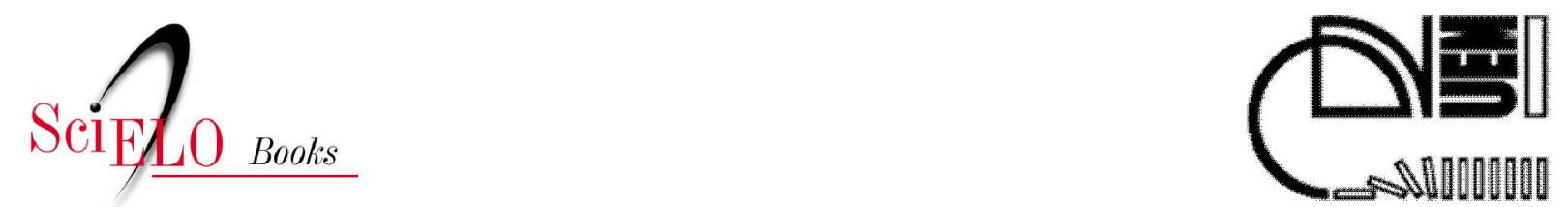

\title{
2 A Revolução Federalista e o cerca da Lapa
}

\author{
Angelo Priori \\ Luciana Regina Pomari \\ Silvia Maria Amâncio \\ Veronica Karina Ipólito
}

\section{@)(1)(0)}

All the contents of this chapter, except where otherwise noted, is licensed under a Creative Commons Attribution-Non Commercial-ShareAlike 3.0 Unported.

Todo o conteúdo deste capítulo, exceto quando houver ressalva, é publicado sob a licença Creative Commons Atribuição Uso Não Comercial - Partilha nos Mesmos Termos 3.0 Não adaptada.

Todo el contenido de este capítulo, excepto donde se indique lo contrario, está bajo licencia de la licencia Creative Commons Reconocimento-NoComercial-CompartirIgual 3.0 Unported. 


\section{2}

\section{A Revolução Federalista e o cerca da Lapa}

O Brasil é uma República Federativa, assim como os Estados Unidos e a Alemanha. O que isso significa? O termo federalismo designa a "forma de governo pela qual vários Estados se reúnem numa só nação, sem perderem sua autonomia fora dos negócios de interesse comum" (FERREIRA, 2010). Sendo assim, os estados do Brasil pertencem à nação brasileira, mas têm autonomia para tomar determinadas decisões, que não ultrapassem os preceitos constitucionais atuais. O regime federalista foi instalado no Brasil com a Proclamação da República em 1889 e é justamente nesse contexto que aconteceu a Revolução Federalista.

Esse movimento teve início no Rio Grande do Sul, em 1893, e envolveu forças políticas prós e contras ao governo do Presidente Floriano Peixoto. Mas, se a revolta foi realizada por gaúchos, por que estudá-la dentro da história do Paraná? Este Estado desenvolveu um papel muito importante no desfecho do conflito. Por isso, vamos compreender as causas e a participação paranaense nessa revolução.

Diferentemente das demais províncias brasileiras, o Rio Grande do Sul teve um povoamento tardio, uma economia voltada para a pecuária e comércio interno. Além disso, presenciou as várias lutas de definição de territórios entre portugueses e espanhóis. Conforme Pereira (2006), 
essas peculiaridades afetaram a política da província rio-grandense: se em um primeiro momento os Partidos Liberal e Conservador se alternaram no governo local durante o Segundo Reinado (1840-1889), com o tempo, o Partido Liberal tornou-se hegemônico, passando a usufruir, sozinho, do poder político provincial. Um dos representantes desse partido foi Gaspar Silveira Martins, que estava em sintonia com o Parlamentarismo desenvolvido por D. Pedro II.

Essa situação contribuiu para o surgimento tardio dos interesses republicanos no Rio Grande do Sul. O Partido Republicano Rio-Grandense (PRR) foi criado apenas em 1882, congregando jovens republicanos de orientação positivista, entre os quais se destacava Júlio Prates de Castilhos. Sendo assim, à época da Proclamação da República (1889), o Partido Republicano local ainda era muito pequeno e sem força política.

O fato de o Marechal Deodoro da Fonseca ter se tornado presidente por meio de um golpe exigia o estabelecimento de alianças políticas para a manutenção do poder. Porém, no Rio Grande do Sul, os liberais, que eram maioria, estavam em sintonia com a monarquia. Diante disso, Deodoro da Fonseca mandou Gaspar Silveira Martins para o exílio e colocou Júlio de Castilhos como presidente da província. Assim, o PRR, inexperiente, assumia a política local, invertendo o jogo político que imperava até então.

No âmbito nacional, esse período de transição foi marcado por intensa crise social e econômica. Além do problema com a mão de obra, gerado pela abolição da escravatura, em 1888, o país enfrentava forte inflação e descontentamento de alguns setores da sociedade, principalmente daqueles que estavam às margens das decisões políticas.

Em 1891 foi promulgada a primeira Constituição da República brasileira que, entre outras coisas, instituiu o sistema federativo e confirmou Deodoro da Fonseca como presidente do país, que deveria governar até 1894, quando haveria eleições diretas para a Presidência da República. Legalizado no poder, o presidente concedeu anistia aos exilados políticos e Gaspar Silveira Martins pôde retornar ao Rio Grande do Sul. 
Porém, o ambiente político partidário gaúcho estava transformado: o positivismo de Júlio de Castilhos imperava no Estado e os antigos liberais já não gozavam de poder político como antes. O sistema federativo instituído pela Constituição republicana de 1891 dava liberdade para os Estados se organizarem. Assim, no Rio Grande do Sul, em junho de 1891, formou-se uma Assembleia Constituinte composta apenas por deputados do PRR. A Constituição, elaborada principalmente por Júlio de Castilhos, foi promulgada em 14 de julho de 1891, mesma data em que Castilhos foi eleito presidente do Estado do Rio Grande do Sul (RIO GRANDE DO SUL, 2012).

Pereira (2006) afirma que a questão central da Revolução Federalista está, justamente, na Constituição de 1891. De caráter estritamente positivista, a Constituição Estadual de 1891 foi promulgada em nome da pátria, da família e da humanidade. Na prática, ela instituiu um poder fortemente centralizado nas mãos do presidente do Estado e permitia ao Legislativo apenas as funções de análise e aprovação do orçamento.

Para Silveira Martins, defensor dos princípios liberais, o governo desenvolvido por Júlio de Castilhos feria a democracia, a liberdade e a participação política. Ele defendia o governo representativo, no qual o Poder Legislativo era o 'poder por excelência' (PEREIRA, 2006). Por isso, a seu ver, o governo castilhista deveria ser extinto. Assim, em 1892, reformulando o antigo Partido Liberal, fundou o Partido Federalista, para fazer oposição a Júlio de Castilhos. O embate político entre os federalistas e os castilhistas deixava o Rio Grande do Sul sob forte tensão. Essa instabilidade tornou-se revolta armada durante o governo presidencial de Floriano Peixoto.

No plano nacional, o autoritarismo de Deodoro da Fonseca gerava muita insatisfação. O presidente chegou a fechar o Congresso. Setores do Exército passaram a fazer-lhe oposição, os ferroviários iniciaram greve, enquanto a crise econômica se intensificava. Diante das pressões, o Marechal renunciou ao poder. Dessa forma, seu vice, o Marechal Floriano Peixoto, assumiu a Presidência da República brasileira. 
Conforme Silva (2005), uma das primeiras medidas de Floriano, enquanto presidente, foi exonerar a maioria dos chefes de governo estaduais que haviam apoiado Deodoro da Fonseca. Essa medida, além de gerar intranquilidade, ainda feria a autonomia dos Estados, pois evidenciava aspectos autoritários e intervencionistas do governo federal. Foi justamente nesse contexto que se desencadeou a Revolução Federalista.

A Constituição Federal de 1891 previa que, caso o cargo de presidente ficasse vago antes de transcorridos dois anos de mandato, o vice deveria assumi-lo por, no máximo, 90 dias, para organizar novas eleições e eleger o novo presidente. Considerando que Deodoro da Fonseca renunciou antes de completar um ano de governo constitucional, Floriano Peixoto deveria cumprir a constituição e organizar novas eleições. Porém, não foi o que o Marechal fez. Pelo contrário, não manifestou a mínima intenção de deixar a presidência. Assim, exonerou os presidentes dos Estados que haviam apoiado Deodoro da Fonseca, ignorando o princípio da autonomia dos mesmos.

Apesar de, no Rio Grande do Sul, Júlio de Castilho ter apoiado Deodoro da Fonseca, a outra facção política local, o Partido Federalista, era radical aos olhos do Marechal Floriano Peixoto. Diante disso, o presidente manifestou apoio a Júlio de Castilhos. Nesse sentido, no plano local, o PRR continuou comandando o poder político. Sem possibilidades de fazer reviver um passado de participação política ativa, os federalistas gaúchos quiseram voltar ao poder por meio da força.

Crise econômica, instabilidade política e ações violentas acirraram-se, culminando, em 1893, com a Revolução Federalista. O grupo dos republicanos ficou conhecido como os 'pica-paus', em virtude do uniforme de seus soldados, que fazia alusão ao bico do pássaro, e os federalistas, desencadeadores da Revolta, ficaram conhecidos como 'maragatos', pois, Silveira Martins e Gumercindo Saraiva - outro membro do Partido Federalista - provinham de uma região do Uruguai colonizada por espanhóis advindos da região da Maragateria, na Espanha. 
Conforme Pereira,

Para os federalistas a Revolução de 1893-1895 foi uma luta com objetivo de derrotar os inimigos da pátria e contra a tirania, em prol da liberdade, da justiça, do império da lei e dos direitos individuais. Para os republicanos, para defender a República, a legalidade, a ordem e o progresso do Estado. Estes tiveram suporte político do governo federal, do jornal A Federação, do Partido Republicano Rio-grandense-PRR, da Brigada Militar e de coronéis da região norte do Estado; os gasparistas tiveram apoio de parte da Marinha, do jornal A Reforma, do Partido Federalista e dos coronéis ou caudilhos da região sul do Rio Grande (2006, p. 159).

No contexto da eclosão da Revolução Federalista, o Presidente Floriano Peixoto colecionava opositores, especialmente da Marinha, na qual se destacava o Almirante Custódio de Melo. Este organizou a Primeira Revolta da Armada contra Deodoro da Fonseca e, então, em 1893, deflagrou a Segunda Revolta da Armada, posicionando-se contrário ao apoio de Floriano Peixoto a Júlio de Castilhos e exigindo o cumprimento da Constituição. Na realidade, Custódio de Melo almejava a presidência da República. Os marinheiros revoltosos formaram focos de conflito no Rio de Janeiro e tomaram a ilha de Desterro (atual Florianópolis), aliando-se aos federalistas do Rio Grande do Sul.

O principal comandante das tropas federalistas era Gumercindo Saraiva. Seu primeiro alvo foi o Estado gaúcho. Tropas concentradas no Uruguai, numa região próxima à cidade de Bagé, iniciaram sua marcha sobre o Rio Grande do Sul com grande violência. Os revoltosos avançaram sobre Santa Catarina e, posteriormente, sobre o Paraná. O objetivo de Gumercindo Saraiva era chegar até o Rio de Janeiro, unir-se aos membros da Revolta da Armada, e tomar o poder.

Porém, os federalistas não constituíam um grupo homogêneo. No geral, apresentavam quatro tendências distintas: 
Os adeptos do almirante Custódio de Mello, responsáveis pela Revolta da Armada, preparavam o golpe; bem sucedido na rebeldia contra Deodoro, que levava o velho marechal à renúncia, Custódio de Mello pretendia substituir Floriano no poder. Já o posicionamento do almirante Saldanha da Gama, herói da Guerra do Paraguai, que aderira à revolta em sua fase final, não escondia inspiração de sabor extravagante: o restabelecimento da monarquia, entregando-se o poder moderador à princesa Isabel. A terceira tendência - majoritária, por sinal - preconizava o parlamentarismo federativo. Eram os adeptos de Gaspar Silveira Martins. E, por último, uma boa parte de libertário, incluindo-se entre eles os caudilhos oriundos do Uruguai (LACERDA, 1985, p. 16).

Assim, embora os federalistas tivessem um posicionamento majoritário, observamos que os próprios revoltosos não conseguiam entrar em harmonia entre si, causando, no decorrer do conflito, falhas na conspiração.

Conforme Silva (2005), o Paraná passou a ter papel importante na Revolução Federalista quando o Presidente Floriano Peixoto decretou Estado de Sítio para os Estados do Sul e convidou o General Francisco de Paula Argolo para organizar o ataque aos revoltosos que já estavam em Santa Catarina. Nesse sentido, o Paraná estava estrategicamente localizado para que as forças legalistas pudessem articular a luta contra os federalistas.

No entanto, as forças militares de que Argolo dispunha eram insuficientes para conter o avanço dos revolucionários. Por isso, o comando da resistência legalista foi transferido para o Coronel Antonio Gomes Carneiro. Conforme orientações do Presidente Floriano Peixoto, o Coronel Carneiro instalou seu quartel-general na cidade de Lapa, de onde organizaria a defesa das cidades paranaenses.

De acordo com Lacerda (1985), o material bélico utilizado pelas forças legalistas era bastante precário, sendo, grande parte, herança da Guerra do Paraguai (1864-1870). Esse problema, somado ao número e às 
condições dos combatentes, prejudicava a resistência dos pica-paus. Nesse sentido, estes não conseguiram evitar a ocupação de algumas cidades paranaenses pelos revolucionários.

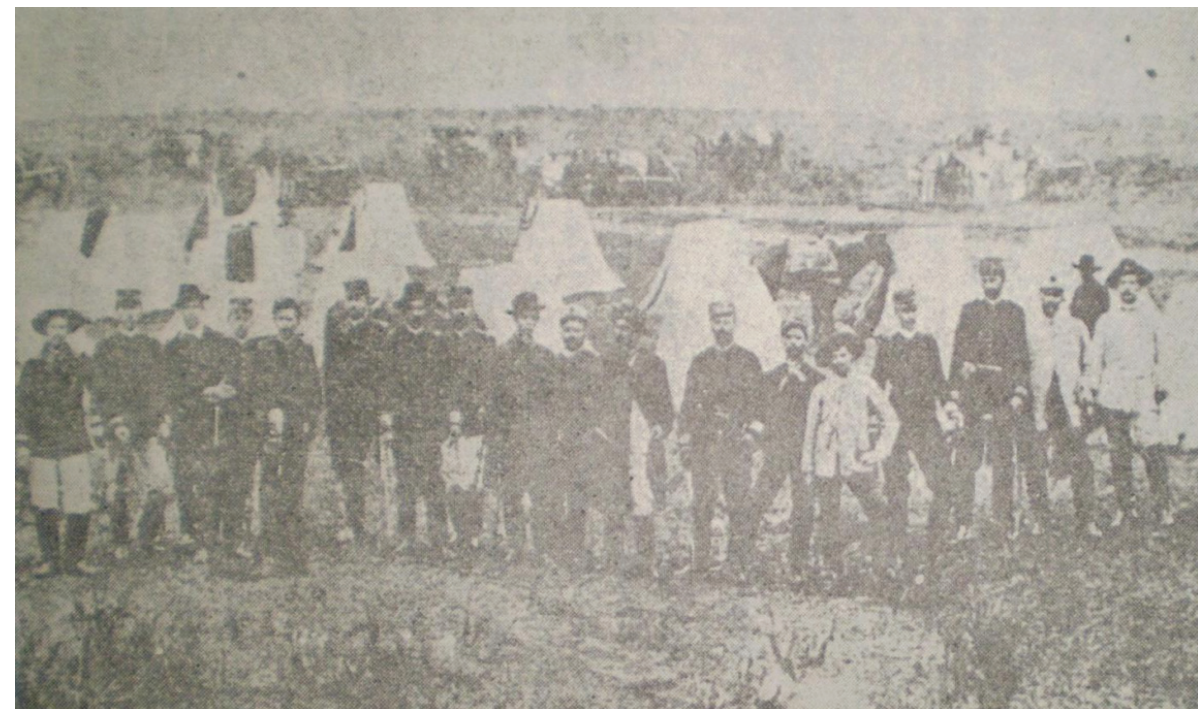

Figura 1: Carneiro, Lacerda e parte da oficialidade, 27 dez. 1893. Fonte: Lacerda (1985, p. 18).

Como a intenção dos federalistas era ocupar os Estados do Sul, avançar sobre São Paulo e tomar o poder no Rio de Janeiro, várias cidades paranaenses tornaram-se alvos dos revolucionários que já haviam tomado Santa Catarina. Sendo assim, cidades como Tijucas, Paranaguá, Curitiba, Ambrózios (atual Tijucas do Sul) e Lapa presenciaram embates mais acentuados entre legalistas e federalistas.

A ação federalista no Paraná se concentrou nos primeiros meses de 1894. Quando Gumercindo Saraiva invadiu a capital paranaense, suas autoridades civis e militares se retiraram, deixando a cidade nas mãos dos revolucionários, sem resistência. O vice-governador do Estado, Vicente Machado, transferiu a Capital para Castro. Os federalistas instalados em Curitiba exigiam dos moradores altas quantias em dinheiro como imposto. 
Para manter a ordem pública nessa cidade, o Barão de Serro Azul criou uma 'Comissão Especial de Empréstimos de Guerra', responsável por cumprir tais exigências (SILVA, 2005, p. 199).

Em Paranaguá, forças da Revolta da Armada chegaram para auxiliar os federalistas vindos do Sul. As forças que guardavam a cidade eram bem menores que os contingentes de marinheiros que desembarcaram e, logo, tomaram os focos de resistência do litoral:

A infantaria de marinha, entusiasmada com os resultados obtidos até aí, avançava pelas ruas da cidade adentro, e, ao encontrar a pequena resistência do canhão da rua 15 , só se satisfizera depois de afogá-la em sangue. A guarnição foi morta à machadinha (CARNEIRO, 1982, p. 139).

Nos primeiros dias janeiro, a cidade de Tijucas também foi alvo de invasões federalistas. Os conflitos armados entre legalistas e revoltosos ocorriam diariamente. Mesmo com os reforços enviados pelo General Carneiro, a cidade não resistiu à ofensiva federalista e capitulou.

Restava, então, somente a resistência em Lapa. A cavalaria federalista cercou essa cidade, interrompeu as comunicações telegráficas e obstruiu suas linhas de rodagem e de ferro. Os legalistas não se encontravam em uma posição confortável. Segundo o General Clemente Argolo Mendes, presente na Lapa durante o cerco,

a posição da cidade era das mais críticas, pois sua defeza (sic) contando com cerca de 700 homens, 4 canhões Krupp, 2 La Hittle e duas metralhadoras Nordenfeldt. Tinha a defender uma parte inteiramente acoberta, cheia de trincheiras, e outra circundada pelo morro do Monge enfiava toda a cidade (CARNEIRO, 1982, p. 171).

Logo após o início dos combates, o General Carneiro ordenou a cavação de trincheiras pela cidade. Reforços militares eram indispensáveis para a manutenção de Lapa. Porém, ainda em janeiro, ele ficou ciente da 
dominação do Estado do Paraná por parte dos federalistas. Os principais centros de resistência, Paranaguá, Curitiba, Tijucas e Ambrósios, haviam caído nas mãos dos revoltosos.

Restando apenas Lapa como foco de resistência legalista, os federalistas iniciaram novo confronto que, segundo o General Carneiro, foi "um dos mais sangrentos na história do Cerco da Lapa" (CARNEIRO, 1982, p. 177). Os federalistas avançaram sobre a cidade e as tropas sitiadas se viram obrigadas a recuar.

Por um lado, os legalistas empreendiam ataques de artilharia. Por outro, os federalistas organizavam incessantes bombardeios que assolavam a cidade diariamente, diminuindo o perímetro de defesa das trincheiras legalistas e causando várias deserções nas tropas do General Carneiro.

No final de janeiro, tropas paulistas, vindas de Itararé, chegaram à Lapa. Entretanto, não foram suficientes para vencer os federalistas, que continuavam avançando cidade adentro, recrudescendo, cada vez mais, os confrontos.

Nos primeiros dias de fevereiro, os invasores consolidaram suas posições e os tiroteios não cessavam. As trincheiras restantes foram destruídas e soldados foram mortos. Os chefes e comandantes das tropas, incluindo o General Carneiro, foram executados. No dia 11 de fevereiro, o Coronel Joaquim Lacerda, observando que as tropas legalistas já não tinham nenhuma condição de resistir, assinou o ofício de capitulação da Lapa.

Durante o Cerco da Lapa, Floriano Peixoto adquiriu equipamentos no exterior, reabastecendo as tropas legalistas de São Paulo. Dessa forma, estas fizeram frente aos federalistas, dando início à retomada legalista do Paraná. Além dos reforços paulistas, os revoltosos "foram impossibilitados de prosseguir, quer pelas divergências internas ou de comandos, quer pelas ideologias diversas que evocavam os dirigentes das forças federalistas. Contribuiu também a desorganização" (SILVA, 2005, p. 199). 
Com o avanço dos florianistas, a revolução foi sendo, aos poucos, suprimida. Muitos revoltosos se exilaram no Uruguai. Porém, esse momento, conforme Silva (2005, p. 199), deu lugar ao "ódio legalista da revanche". Ao contrário do que possamos imaginar, as atrocidades foram cometidas de ambos os lados. Após a vitória legalista, muitas prisões e mortes aconteceram. A título de exemplo vale destacar dois episódios: o fuzilamento do Barão de Serro Azul, acusado de ter sido conivente com os revoltosos em Curitiba, e o decepamento da cabeça de Gumercindo Saraiva, cujo cadáver foi desenterrado pelos legalistas para cometerem tal vingança.

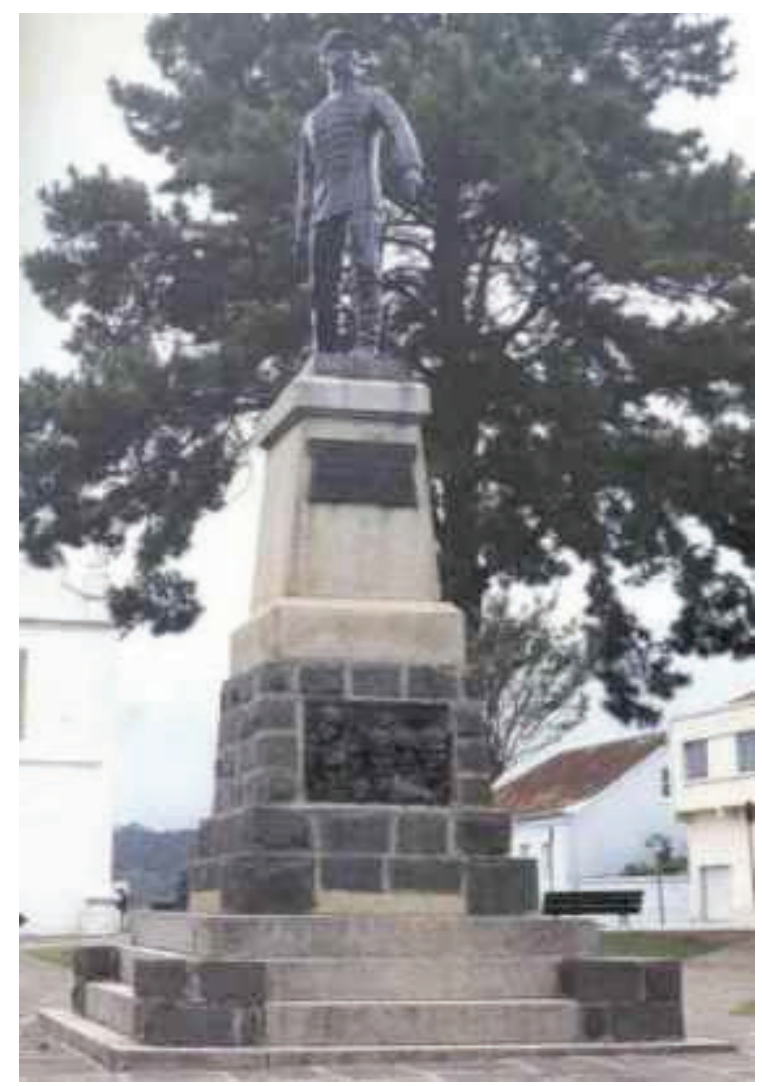

Figura 2: Monumento ao General Antônio Ernesto Gomes Carneiro, Lapa. Fonte: Salles Pousada (2012). 
A resolução final do conflito aconteceu apenas em 1895, quando o Presidente Prudente de Morais selou um acordo de paz com os federalistas na cidade de Pelotas-RS. Assim, os castilhistas foram vitoriosos, exercendo poder político no Rio Grande do Sul até a década de 1930.

Em termos políticos, o Paraná desenvolveu importante papel no contexto da Revolução Federalista. A resistência articulada pelo General Carneiro na cidade de Lapa permitiu que os reforços governistas se organizassem contra os revoltosos, contribuindo para a manutenção da República presidencialista no Brasil.

\section{Referências}

CARNEIRO, David. O Paraná e a Revolução Federalista. 2. ed. Curitiba: Secretaria da Cultura e do Esporte: Indústria Gráfica Gonçalves, 1982.

FERREIRA, Aurélio Buarque de Holanda. Novo Dicionário Aurélio: versão eletrônica. 5. ed. Curitiba: Positivo, 2010. Disponível em: <http://www.educacional.com.br/ dicionarioaurelio/>. Acesso em: 24 jan. 2012.

LACERDA, Francisco Brito. O Cerco da Lapa: do princípio ao fim. Curitiba: Secretaria de Estado da Cultura do Paraná, 1985.

PEREIRA, Ledir de Paula. O positivismo e o liberalismo como base doutrinária das fações políticas gaúchas na revolução federalista de 1893-1895 e entre Maragatos e Chimangos de 1923. 2006. 173 f. Dissertação (Mestrado em Ciência Política) - UFRGS, Porto Alegre, 2006. Disponível em: < http://www.lume.ufrgs.br/bitstream/ handle/10183/12772/000633681.pdf?sequence=1 > . Acesso em: 24 jan. 2012.

RIO GRANDE DO SUL. Memorial do Legislativo. Porto Alegre: Assembléia Legislativa, 2012. Disponível em: <<http://www2.al.rs.gov.br/memorial/ARep\%C3\%BAblicaea Constitui \%C3\%A7\%C3\%A3oEstadualde1891/tabid/3466/language/pt-BR/Default. aspx>. Acesso em: 23 jan. 2012.

SALLES Pousada. Disponível em: < http://www.sallespousada.com.br/turismo2.htm>. Acesso: 12 jun. 2012.

SILVA, Luiz César Kreps. Revolução Federalista. In: SCORTEGAGNA, Adalberto; REZENDE, Cláudio Joaquim; TRICHES, Rita Inocêncio (Org.). Paraná, espaço e memória: diversos olhares histórico-geográficos. Curitiba: Bagozzi, 2005. p. 182-203. 